\section{Gender differences in child nutrition status of Bangladesh: a multinomial modeling approach}

\section{Multinomial modeling approach}

\author{
Iqramul Haq
}
Department of Agricultural Statistics, Sher-e-Bangla Agricultural University, Dhaka, Bangladesh

Md. Ismail Hossain, Mst. Moushumi Parvin, Ahmed Abdus Saleh Saleheen and Md. Jakaria Habib Jagannath University, Dhaka, Bangladesh, and

Imru- Al-Quais Chowdhury

Armed Forces Medical Institute, Dhaka Cantonment, Dhaka, Bangladesh
Received 12 February 2021 Revised 2 May 2021 22 May 2021 Accepted 22 May 2021

\begin{abstract}
Purpose - Malnutrition is one of the serious public health problems especially for children and pregnant women in developing countries such as Bangladesh. This study aims to identify the risk factors associated with child nutrition for both male and female children in Bangladesh.

Design/methodology/approach - This study was conducted among 23,099 mothers or caretakers of children under five years of age from a nationally representative survey named Bangladesh Multiple Indicator Cluster Survey, 2019. This study used chi-square test statistic for bivariate analysis and multinomial logistic regression was used to evaluate the adjusted effects of those covariates on child nutritional status.

Findings - The prevalence of severely malnourished, nourishment was higher for males than females $(5.3 \%$ vs $5.1 \%, 77.4 \%$ vs $76.8 \%)$ while moderately malnourished were higher for females $(18.1 \%$ vs $17.4 \%)$. The findings from the multinomial model insinuated that the mother's education level, wealth index, region, early child development, mother's functional difficulties, child disability, reading children's books and diarrhea had a highly significant effect on moderate and severe malnutrition for male children. For the female children model, factors such as mother's education level, wealth index, fever, child disability, rural, diarrhea, early child development and reading less than three books were significant for moderate and severe malnutrition.
\end{abstract}

(C) Iqramul Haq, Md. Ismail Hossain, Mst. Moushumi Parvin, Ahmed Abdus Saleh Saleheen, Md. Jakaria Habib and Imru- Al-Quais Chowdhury. Published in Journal of Humanities and Applied Social Sciences. Published by Emerald Publishing Limited. This article is published under the Creative Commons Attribution (CC BY 4.0) licence. Anyone may reproduce, distribute, translate and create derivative works of this article (for both commercial and non-commercial purposes), subject to full attribution to the original publication and authors. The full terms of this licence maybe seen at http:// creativecommons.org/licences/by/4.0/legalcode

Special thanks to the United Nations Children's Fund (UNICEF) for allowing the use of the Bangladesh Multiple Indicator Cluster Survey in our research. Thanks also to the Humanitarian Data Exchange (https://data.humdata.org/) for allowing the use of the Bangladesh-subnational Administrative Boundaries shape file.

Funding: This research did not receive any specific grants from the government, commercial, or non-profit sector funding agencies.

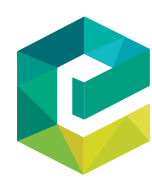

Journal of Humanities and Applied Social Sciences Vol. 4 No. 5,2022 pp. $379-392$ Emerald Publishing Limited 2632-279X DOI 10.1108/JHASS-02-2021-0030 

JHASS
4,5

Originality/value - There is a solution to any kind of problem and malnutrition is not an exceptional health problem. So, to overcome this problem, policymakers should take effective measures to improve maternal education level, wealth status, child health.

Keywords Malnutrition, Nutrition, Nourished, Weight-for-age

Paper type Research paper

\section{Introduction}

Nutrition status can be the most powerful predictor of prosperity for children (Poda et al., 2017). A healthy child can become a worthy human resource of a country. That is why it is very important to ensure the adequate nutrition of children. Yet, unfortunately, very few of them get adequate nutrition in developing countries.

Children with extreme acute malnutrition have a higher chance of dying from childhood diseases such as diarrhea, pneumonia and malaria. Around $45 \%$ of deaths among children under five years of age are due to malnutrition, which typically occurs in low- and middleincome countries (World Health Organization, 2018). Not entirely exact, but close to 3.1 million children die from malnutrition each year. In particular, undernutrition leads to more than half the deaths of children worldwide (International Food Policy Research Institute, 2015; UNICEF, 2018). Malnutrition refers to a human body nutritional imbalance disorder that can be of both forms, under-nutrition and over-nutrition, as well as associated diseases (Toma et al., 2018). Wasting, stunting, underweight and vitamin and mineral deficiencies are some typical sub-forms of undernutrition (World Health Organization, 2020).

Developing countries are the most dominant place of child malnutrition, although it remains worldwide (Mahgoub et al., 2006). According to Bangladesh Demographic and Health Survey (BDHS) 2007, in Bangladesh, $43 \%$ and $41 \%$ of children were stunted and underweight, respectively (National Institute of Population Research and Training (NIPORT), Mitra and Associates and Macro International, 2009). Despite the government's target to reach Millennium Development Goals (MDGs) goal related to child nutrition, the proportion of underweight children is still above the target which is $33 \%$ by 2015 in the Sylhet, Barisal, Chittagong and Rangpur divisions (Das et al., 2018). According to a recent study of child malnutrition in Bangladesh based on small area estimation, the stunting level ranged between $34 \%$ and $48 \%$ at the district level and $28 \%$ to $51 \%$ at the sub-district level (Haslett et al., 2015). Moreover, the BDHS-2014 data reveals that the frequency of stunted and underweight children is one per every three children; on the other hand, one in every seven children is wasted. While male children and children of age 12-59 months are at high risk to be stunted (Rahman and Sultana, 2019).

The sex of the child, age, type of birth, health, age of the mother, education and body mass index (BMI), household wealth index, number of children under five years, place of child delivery, place of residence can have a major effect on a child's nutritional status (Poda et al., 2017). There is a strong association between the BMI of the mother and her child's nutritional status (Negash et al., 2015; Felisbino-Mendes et al., 2014). A joint report by United Nations Children's Fund (UNICEF) and WHO states that worldwide 101 million children are underweight and about 34 million children in Asia are wasted (Shrestha et al., 2020; de Onis et al., 2011).

In Southeast Asia, Bangladesh is one of the top ten countries with the largest number of under-five child deaths (in thousands) (World Health Organization, 2020). The recent findings of the Bangladesh Bureau of Statistics (BBS) and UNICEF (2019) indicate a favorable outcome for chronic malnutrition (Bangladesh Bureau of Statistics (BBS) and UNICEF, 2019). In recent years, the percentage of stunting children has decreased from $42 \%$ 
to $28 \%$, whereas the percentage of moderate and severe underweight prevalence rate has declined to $22.6 \%$ (UNICEF, 2020).

In the past, most researchers had used different strategies and different statistical models to determine the risk factors for child malnutrition. Most of the studies used the binary logistic regression model (Khadse and Chaurasia, 2020; S and K, 2016). In this study, as we classified child nutritional status as severely malnourished, moderately malnourished and nourished, so we can apply the ordinal logistic regression model to determine the causes of child malnutrition (Das and Rahman, 2011). Alternatively, multinomial logistic regression can be applied if the order information is ignored to compare with ordinal logistic regression for selecting the best model.

Therefore, it is clear from the above discussion that Bangladesh's new task is to maintain the consistency of progress and look forward to achieving the sustainable development goals (SDGs) by 2030. To address this situation, we must identify the factors which are responsible for child malnutrition, especially considering male children and female children separately. The current study aimed to examine the influence of sociodemographic and economic factors on child nutritional status both in male and female children of Bangladesh and identify important factors with their adjusted effects using data from the Bangladesh 2019 Multiple Indicator Cluster Surveys (MICS) and moving toward to SDGs Target 2. In this paper, we applied both Ordinal and Multinomial logistic regression models and considered Akaike information criteria (AIC) and Bayesian information criteria (BIC) techniques to identify the best model.

\section{Conceptual framework}

Several studies have found that socio-demographic characteristics such as wealth index, mother's education, place of residence, region were associated with child nutritional status (Das and Rahman, 2011; Saha et al., 2019; Rahman, 2016a, 2016b; Megabiaw and Rahman, 2013). Earlier several studies identified potential risk factors associated with children's nutritional status were children's disability, recent diarrhea and fever (Kuper et al., 2015; Hume-Nixon and Kuper, 2018; Das and Rahman, 2011; Ferdous et al., 2013). Alongside, Mother's functional disability, early childhood developments (ECD), early childhood education, the reading book to children were also considered as the possible risk factors for children's nutrition status in this analysis. Figure 1 portrays the pathway through which socio-demographic factors and proximate determinants were likely to operate to influence child nutrition status. Socio-demographic characteristics that affect child nutrition were not only influence directly but also indirectly through proximate determinants. Among them, proximate determinants of children's nutrition status, child health, maternal health and child development were considered in this analysis and also indicate that it was directly influenced children's nutrition status in Bangladesh (Figure 1).

\section{Methodology}

\subsection{Study design and sample selection}

For our analysis purpose, we extracted relevant information from the 2019 Bangladesh MICS on children's nutritional status, which was conduct through a joint effort between the Bangladesh Bureau of Statistics (BBS) and UNICEF (Bangladesh Bureau of Statistics (BBS) and UNICEF, 2019). Bangladesh MICS-2019 has used a two-stage stratified cluster sampling approach, which is similar to Bangladesh Census of Population and Housing, 2011 (Bangladesh Bureau of Statistics (BBS) and UNICEF, 2019). At the first stage, 3,220 enumeration areas (EAs) were defined for the census enumeration which was the primary sampling units. A systematic sample of 20 households was drawn from each sampled EAs and 64,400 households were selected in the second stage while 24,686 mothers/caretakers were qualified from these sampled households. We applied sample weight to the MICS data 


\section{JHASS \\ 4,5}

\section{2}

Figure 1.

Conceptual framework for child nutrition status

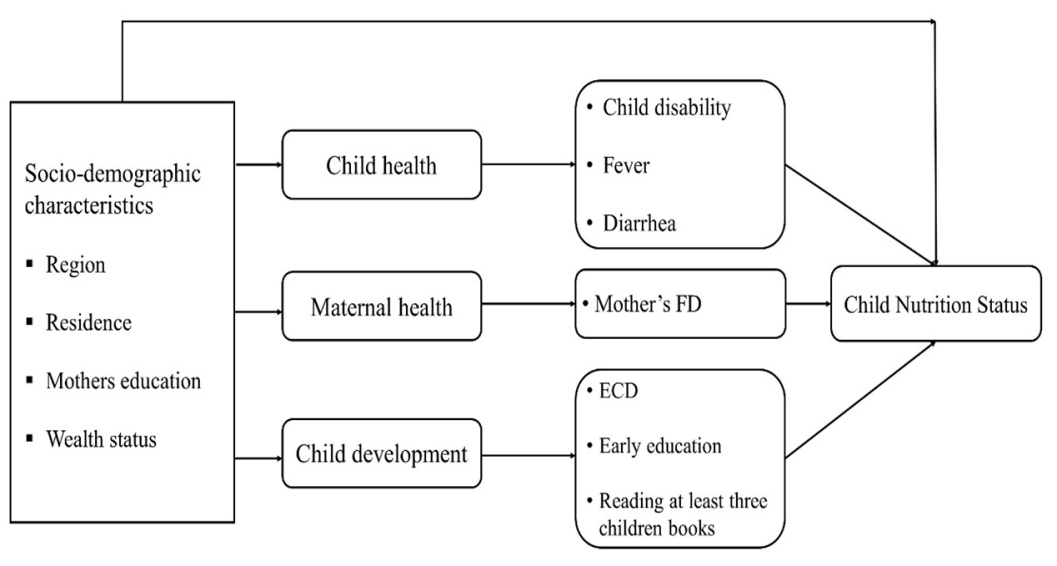

for a true representation of the research findings. After being weighed, the sample size of this study was approximately 23,099 mothers/caretakers who had children under five years of age. Among the mothers/caretakers who were interviewed in the whole of Bangladesh, 11,950 had male and 11,149 had female children below five years of the inquiry fields (Bangladesh Bureau of Statistics (BBS) and UNICEF, 2019). The flowchart of the selection of children is given as follows (Figure 2).

The whole population of Bangladesh with the sampling frame of the list of EAs prepared for the 2011 population and housing census

Selection of 3220 enumeration areas (EAs) which is the primary sampling unit

At the second stage, a systematic sample of 20 households (on average) was drawn from each sample EAs

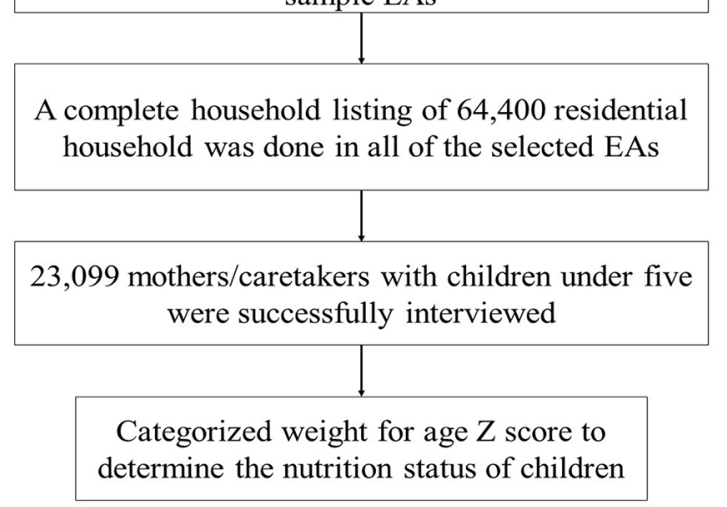

Figure 2.

Flowchart of target sample selection in this study 


\subsection{Variables}

Outcome variable. In 2019, MICS Bangladesh used anthropometric measurement technique for assessing nutritional status by measuring weight and height of under-five children and common indicators were height for age $Z$ score, weight for age $Z$ score and weight for height $Z$ score to determine the nutritional health of children. Among these three indicators, we used weight for age $Z$ score as a dependent variable named child nutritional status which was categorized as, severely malnourished (WAZ $<-3.0$ ); moderately malnourished $(-3.0<\mathrm{WAZ}<-2.01$ ); nourished $(\mathrm{WAZ}>-2.01)$

Explanatory variables. In the established multivariate model, a set of socioeconomic and demographic factors related to child nutritional status were considered as covariates. As for our study, region (Central, East and West), residence (Urban and Rural), mother's education level (no education, primary education, secondary and above education), wealth status (poor, middle, rich), attendance to early childhood education (attending, not attending), early childhood development (Yes, No), reading children's books ( $\geq 3$ books, $<3$ books), functional difficulties for mothers and children (Yes, No), fever (Yes, No) and diarrhea (Yes, No) were selected as independent variables.

The ECD characterized the development index of children aged from 36 to 59 months and was measured using four domains, namely, literacy-numeracy, physical, social-emotional and learning. Analyzed ECD compliance for each child $i$, aged 36 to 59 months, in Bangladesh, that assures at least 3 out of 4 domains. That is,

$$
E C D_{i}= \begin{cases}1 ; & \text { if } \sum_{r=1}^{4} d_{i, r} \geq 3 \\ 0 ; & \text { otherwise }\end{cases}
$$

The ECD index defined the percentage of children aged 36 to 59 months old and was calculated using four areas/domains, including literacy-numeracy, physical, socialemotional and learning. Among four domains, The ECDI is the proportion of children who were developmentally on track in at least three domains.

\subsection{Data analysis}

For our study, we divided the whole analysis part into two sections, one is for male children and the other is for only female children. The chi-square test was used to examine the association between selected covariates and child nutritional status. In this study, we framed two types of the logistic regression model in multivariate cases such as the ordinal logistic regression model and multinomial logistic regression model, and finally, the odds ratio was calculated with a 95\% confidence interval (Kleinbaum and Klein, 2010).

Additionally, two different ordinal regression models and two different multinomial regression models were generated, one for males and the other for the female who was under-five children, and finds the best model using AIC and BIC techniques in this case. A good model is the one with the least value of AIC and BIC among all other models (Mohammed et al., 2015). BIC's goal is to find the best model for prediction with the highest posterior likelihood, while AIC's goal is to find the model that most plausibly produced the results. Finally, we compare the differences to assess the impact of sociodemographic factors between the two genders.

The Statistical Package for Social Science 25 version and R-programming version 4.0.0 were applied for data management, analysis and geographical mapping. For geographical mapping, we use "sf" and "ggplot2" package. 
JHASS

4,5

384

3.3.1 Ethical consideration. In this study, we used MICS-2019 data downloaded from the MICS. A special thank goes to the UNICEF for enabling us to use Bangladesh MICS for our study from http://mics.unicef.org/. During the data collection, MICS maintained the privacy and confidentiality of respondents and at the beginning of individual interviews, respondents were given an informed consent form. Therefore, as this study was focused on public use, no further ethical approval was required for our data analysis.

\section{Results}

\subsection{Geographical illustration of child nutrition status}

This study found that, among male children, 5.3\% were severely malnourished, $17.4 \%$ moderately nourished and $77.4 \%$ were nourished. However, among the female children, $5.1 \%$ were severely malnourished, $18.1 \%$ were moderately malnourished and $76.8 \%$ were nourished.

Figures 3 and 4 demonstrate that the divisional variation of under-five children in Bangladesh. Here we represent different maps for different nutritional statuses.

\subsection{Result of bivariate analysis}

Table 1 represents the results of bivariate analysis and the covariates region, residence, maternal education level, wealth index, early childhood development, early education, read children books and child disability were significantly associated with child nutritional status for both male and female. Although the covariates, namely, fever (for male), functional

\section{Nutrition status among under-five male children}

Figure 3.

Spatial presentation of nutritional status among under-five male children in Bangladesh
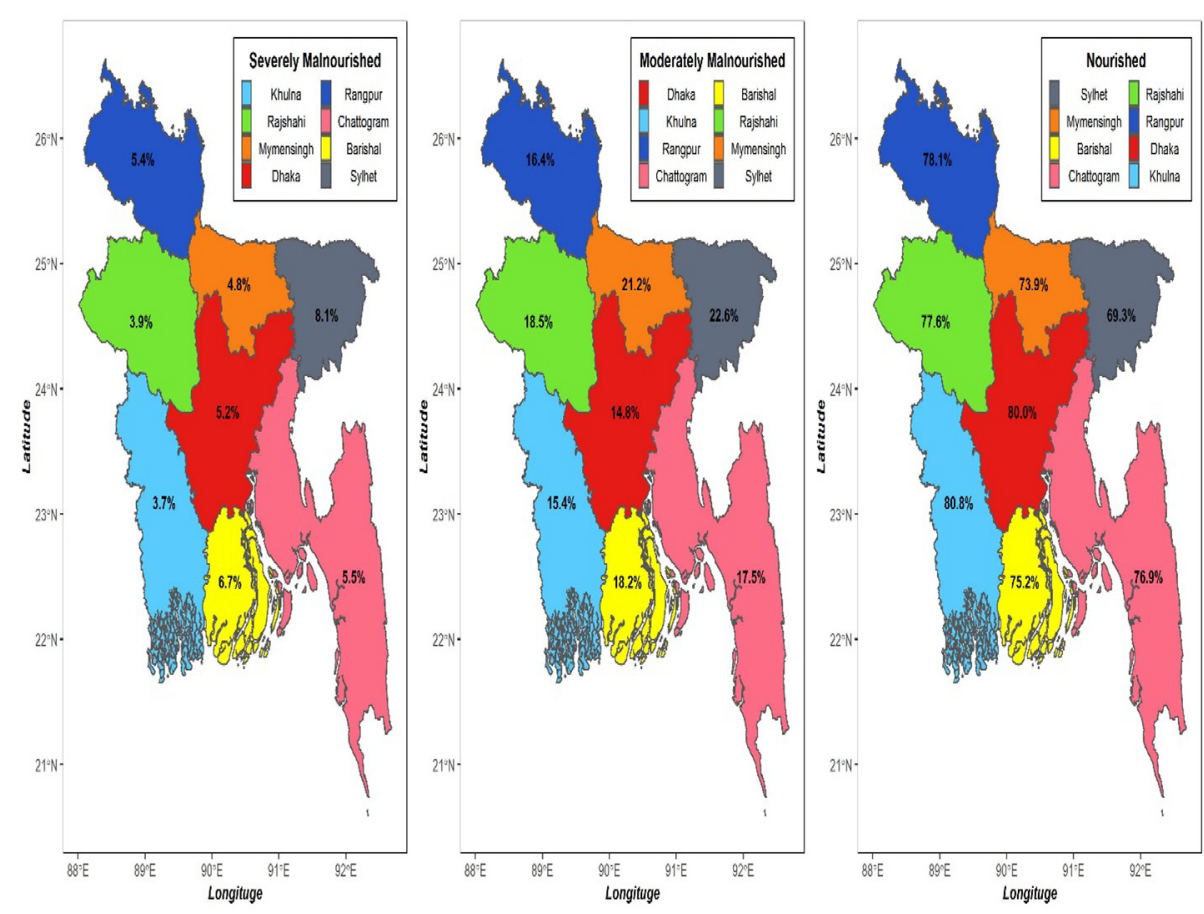

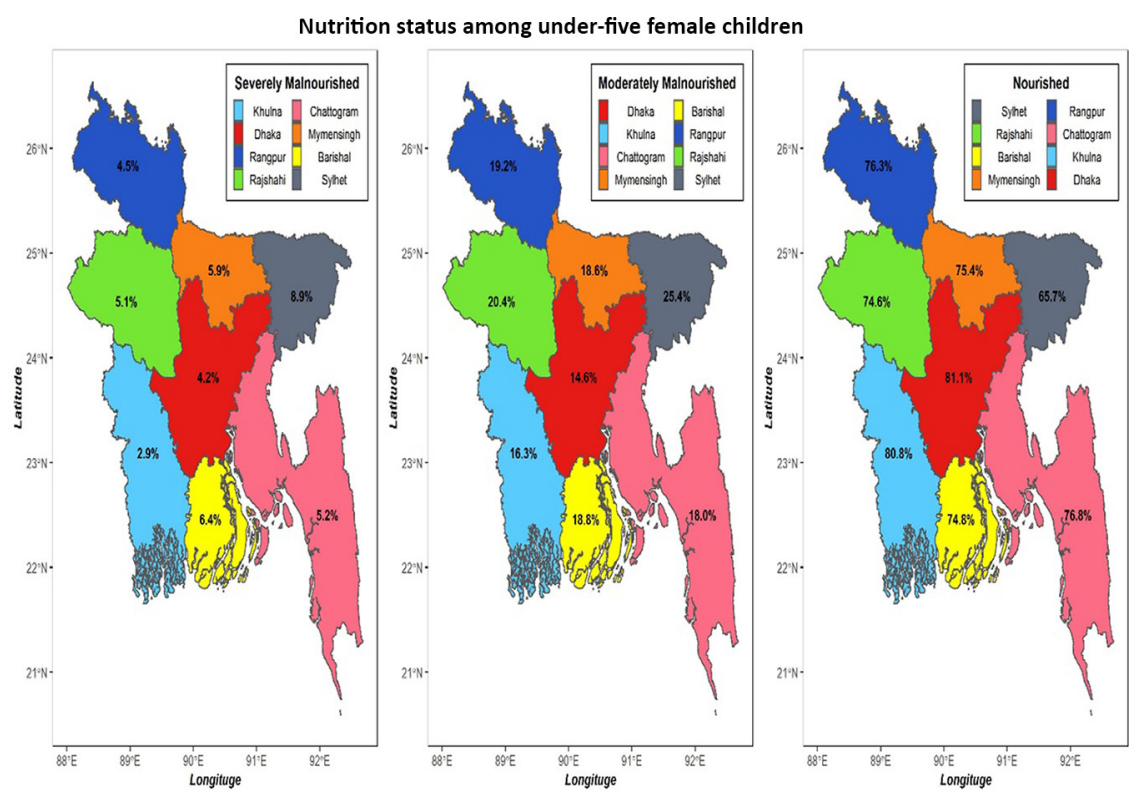

Multinomial modeling approach

385

Figure 4.

Spatial presentation of nutritional status among under-five female children in Bangladesh

difficulties of mother and child disabilities (for female) were not significant in bivariate analysis, we included multivariate analysis.

The percentages of severely and moderately malnourished children were found higher in the east region $(6.1 \%$ and $18 \%$, respectively for male and $6.0 \%$ and $18.8 \%$, respectively for female). A greater percentage of severely and moderately malnourished children lived in rural areas $(5.3 \%$ and $16.9 \%$, respectively for male and $5.4 \%$ and $18.3 \%$, respectively for female).

We also found higher percentages of severely and moderately malnourished children for uneducated mother $(8.7 \%$ and $22.3 \%$, respectively for male and $7.1 \%$ and $24.7 \%$, respectively for female), poor household ( $6.8 \%$ and $20.2 \%$, respectively for male and $6.7 \%$ and $21.7 \%$, respectively for female), no early child development $(5.4 \%$ and $19.9 \%$, respectively for male and $6.5 \%$ and $21.9 \%$, respectively for female), not early child education $(4.5 \%$ and $19 \%$, respectively for male and $5.5 \%$ and $21.5 \%$, respectively for female), not reading three or more children books $(5.4 \%$ and $16.9 \%$, respectively for male and $5.2 \%$ and $17.3 \%$, respectively for female), having child disability $(5.9 \%$ and $24.5 \%$, respectively for male and $5.1 \%$ and $23.7 \%$, respectively for female), having mother's functional disability (8.6\% and $15.2 \%$, respectively for male and $5.7 \%$ and $17.8 \%$, respectively for female), children having fever $(5.6 \%$ and $17.4 \%$, respectively for male and $6.6 \%$ and $18.7 \%$, respectively for female) and diarrhea $(7.8 \%$ and $19.7 \%$, respectively for male and $7.5 \%$ and $19.0 \%$, respectively for female).

\subsection{Best model selection}

Table 2 represent different logistic regression model for children nutritional status in terms of their sex. The selections of the best model were performed according to the principle of AIC and BIC. From Table 2 we can see that multinomial logistic regression was the best, in this case, as the AIC and BIC values were lower compared to ordinal logistic regression. 


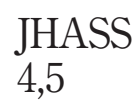

386

\begin{tabular}{|c|c|c|c|c|c|c|}
\hline Background factors & $\begin{array}{c}\text { Severely } \\
\text { malnourished } \\
(\%)\end{array}$ & $\begin{array}{c}\text { Male } \\
\text { Moderately } \\
\text { malnourished } \\
(\%)\end{array}$ & $\begin{array}{c}\text { Nourished } \\
(\%)\end{array}$ & $\begin{array}{l}\text { Severely malnourished } \\
\qquad(\%)\end{array}$ & $\begin{array}{l}\text { emale } \\
\text { Moderately } \\
\text { malnourished } \\
(\%)\end{array}$ & $\begin{array}{c}\text { Nourished } \\
(\%)\end{array}$ \\
\hline \multicolumn{7}{|l|}{ Region } \\
\hline Central & 5.3 & 15.9 & 78.9 & 5.0 & 15.4 & 79.7 \\
\hline East & 6.1 & 18.0 & 75.9 & 6.0 & 18.8 & 75.2 \\
\hline West & 4.3 & 16.0 & 79.6 & 4.2 & 17.7 & 78.1 \\
\hline$p$-value & $<0.001$ & & & $<0.001$ & & \\
\hline \multicolumn{7}{|l|}{ Residence } \\
\hline Urban & 4.6 & 15.2 & 80.2 & 3.5 & 12.8 & 83.7 \\
\hline Rural & 5.3 & 16.9 & 77.7 & 5.4 & 18.3 & 76.2 \\
\hline$p$-value & 0.03 & & & $<0.001$ & & \\
\hline \multicolumn{7}{|l|}{ Mothers education } \\
\hline No education & 8.7 & 22.3 & 69.0 & 7.1 & 24.7 & 68.2 \\
\hline Primary & 6.3 & 19.1 & 74.6 & 7.1 & 20.7 & 72.1 \\
\hline Secondary+ & 4.2 & 14.6 & 81.2 & 3.9 & 14.6 & 81.5 \\
\hline & & & & & & \\
\hline \multicolumn{7}{|l|}{ Wealth index } \\
\hline Poor & 6.8 & 20.2 & 73.0 & 6.7 & 21.7 & 71.5 \\
\hline Middle & 4.0 & 16.6 & 79.4 & 4.4 & 17.6 & 78.0 \\
\hline Rich & 4.0 & 12.8 & 83.2 & 3.6 & 12.2 & 84.2 \\
\hline$p$-value & $<0.001$ & & & $<0.001$ & & \\
\hline \multicolumn{7}{|l|}{$E C D$} \\
\hline Yes & 3.5 & 17.1 & 79.3 & 4.6 & 19.8 & 75.6 \\
\hline & 5.4 & 19.9 & 74.7 & 6.5 & 21.9 & 71.6 \\
\hline$p$-value & $<0.001$ & & & 0.01 & & \\
\hline \multicolumn{7}{|l|}{ Early education } \\
\hline Yes & 2.0 & 13.7 & 84.3 & 2.9 & 15.5 & 81.5 \\
\hline & 4.5 & 19.0 & 76.5 & 5.5 & 21.5 & 73.1 \\
\hline$p$-value & $<0.001$ & & & $<0.001$ & & \\
\hline \multicolumn{7}{|l|}{ Read child books } \\
\hline$\geq 3$ books & 2.4 & 10.7 & 86.9 & 2.2 & 14.7 & 83.1 \\
\hline$<3$ books & 5.4 & 16.9 & 77.7 & 5.2 & 17.3 & 77.5 \\
\hline$p$-value & $<0.001$ & & & $<0.001$ & & \\
\hline \multicolumn{7}{|l|}{ Child disability } \\
\hline Yes & 5.9 & 24.5 & 69.6 & 5.1 & 23.7 & 71.2 \\
\hline No & 4.6 & 17.8 & 77.5 & 5.3 & 19.9 & 74.8 \\
\hline$p$-value & 0.01 & & & 0.495 & & \\
\hline \multicolumn{7}{|l|}{ Mother's FD } \\
\hline Yes & 8.6 & 15.2 & 76.2 & 5.7 & 17.8 & 76.5 \\
\hline & 5.1 & 16.6 & 78.3 & 5.0 & 17.1 & 77.9 \\
\hline$p$-value & 0.004 & & & 0.776 & & \\
\hline \multicolumn{7}{|l|}{ Fever } \\
\hline Yes & 5.6 & 17.4 & 77.0 & 6.6 & 18.7 & 74.7 \\
\hline No & 5.1 & 16.3 & 78.7 & 4.6 & 16.7 & 78.7 \\
\hline$p$-value & 0.174 & & & $<0.001$ & & \\
\hline \multicolumn{7}{|l|}{ Diarrhea } \\
\hline Yes & 7.8 & 19.7 & 72.6 & 7.5 & 19.0 & 73.5 \\
\hline & 5.0 & 16.3 & 78.7 & 4.8 & 17.0 & 78.1 \\
\hline$p$-value & $<0.001$ & & & 0.001 & & \\
\hline
\end{tabular}

Table 1.

Cross tabulation socioeconomicdemographic variables and nutritional status among children under-five

Notes: Statistical significance: ${ }^{*} p<0.05,{ }^{* * *} p<0.01,{ }^{* * * *} p<0.001$ 


\subsection{Result of multivariate analysis}

Table 3 evaluates the effectiveness of the covariates by the multivariate multinomial logistic regression model. All the independent variables included in the analysis manifested to have significant interconnection with outcome variables.

The adjusted effects for child nutritional status based on socio-demographic factors among children below five years of age for both males and females in Bangladesh using the multinomial regression model are presented in Table 3.

Our findings from Table 3 at least hint that, for the male under-five children, there were

Multinomial modeling approach

387 significant $(p<0.001, p<0.01, p<0.05$ ) effects of mother's education level, wealth index, east region, ECD and diarrhea on both moderate and severe malnutrition. From the result, it is clear that the effects of mother's functional difficulties $(\mathrm{OR}=0.69)$ and west region $(\mathrm{OR}=$ 0.82 ) were stronger on severely malnourished compared to moderately malnourished for under five male children. Also, we found a significant connection between moderate malnutrition and several factors such as child disability $(\mathrm{OR}=1.21)$, early education $(\mathrm{OR}=$ $1.24)$ and reading children's books $(\mathrm{OR}=1.51)$ for male children.

In addition, we obtained good results with multivariate multinomial logistic regression method for female under-five children which were shown in Table 3 . The results indicate that there were significant $(p<0.001, p<0.01, p<0.05$ ) effects of wealth index, mother's education in secondary and above level, child disability, rural and early education on both moderate and severe malnutrition. Our result demonstrated that diarrhea, and ECD, reading less than three books to children exhibited a significant effect on severely malnourished female children.

\section{Discussion}

In this study, we are comparing the child nutritional status of under-five children for both males and females. The bivariate findings revealed highly significant association between nutritional status for both male and female under-five children and several factors such as mother's education, wealth index, region, place of residence and this finding is consistent with the existing study (Toma et al., 2018; Rahman, 2016a, 2016b; Srivastava et al., 2012; Mostafa Kamal et al., 2010).

Child nutritional status for both male and female children were significantly associated with ECD, early education, reading book and recent diarrhea. Mother's functional disability had a significant impact on nutritional level for male under-five children.

A mother's level of education is the key to the nutritional status of the children. Women's education is significantly negatively associated with children's nutrition status in both female and male children in Bangladesh. Multivariate analysis shows that children who had a mother with higher education and a household with a higher wealth index were less likely to be malnourished compared with the reference group for both male and female children. The outcome was comparable or marginally higher in this study than in the previous study (Poda et al., 2017; Rahman, 2016a, 2016b; Rayhan and Khan, 2006; Talukder, 2017). The

\begin{tabular}{|c|c|c|c|c|}
\hline \multirow[b]{2}{*}{ Model } & \multicolumn{2}{|c|}{ Male } & \multicolumn{2}{|c|}{ Female } \\
\hline & AIC & $\mathrm{BIC}$ & AIC & $\mathrm{BIC}$ \\
\hline Ordinal logistic regression & $15,182.2$ & $15,332.5$ & $13,962.4$ & $\begin{array}{l}14,079.4 \\
14073\end{array}$ \\
\hline Multinomial logistic regression & $15,158.5$ & $15,308.3$ & $13,956.5$ & $14,073.0$ \\
\hline
\end{tabular}

Notes: $\mathrm{AIC}=$ Akaike information criterion, $\mathrm{BIC}=$ Bayesian information criterion
Table 2.

Comparison table of different statistical model 


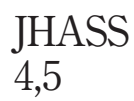

388

\begin{tabular}{|c|c|c|c|c|}
\hline \multirow[b]{2}{*}{$\begin{array}{l}\text { Background } \\
\text { factors }\end{array}$} & \multicolumn{2}{|c|}{ Male } & \multicolumn{2}{|c|}{ Female } \\
\hline & $\begin{array}{c}\text { Severely vs } \\
\text { nourished } \\
\text { OR }[95 \% \mathrm{CI}] \\
\text { ( } p \text {-value) }\end{array}$ & $\begin{array}{c}\text { Moderately vs } \\
\text { nourished } \\
\text { OR }[95 \% \mathrm{CI}] \\
(p \text {-value })\end{array}$ & $\begin{array}{c}\text { Severely vs } \\
\text { nourished } \\
\text { OR }[95 \% \mathrm{CI}] \\
\text { ( } p \text {-value })\end{array}$ & $\begin{array}{c}\text { Moderately vs } \\
\text { nourished } \\
\text { OR [95\% CI] } \\
\text { ( } \text {-value) }\end{array}$ \\
\hline $\begin{array}{l}\text { Region } \\
\text { Central (ref.) }\end{array}$ & 1 & 1 & 1 & 1 \\
\hline $\begin{array}{l}\text { East } \\
\text { West }\end{array}$ & $\begin{array}{l}1.21[1.01-1.49] \\
(0.04) \\
0.82[0.66-1.00] \\
(0.049)\end{array}$ & $\begin{array}{l}1.17[1.04-1.32] \\
(0.009) \\
0.95[0.84-1.07] \\
(0.35)\end{array}$ & $\begin{array}{l}1.26[1.02-1.54] \\
(0.03) \\
0.83[0.66-1.03] \\
(0.09)\end{array}$ & $\begin{array}{l}1.27[1.12-1.44] \\
(<0.001) \\
\quad 1.10[0.97-1.25] \\
(0.13)\end{array}$ \\
\hline $\begin{array}{l}\text { Residence } \\
\text { Urban (ref.) }\end{array}$ & 1 & 1 & 1 & 1 \\
\hline Rural & $\begin{array}{l}0.92[0.73-1.16] \\
(0.47)\end{array}$ & $\begin{array}{l}0.89[0.77-1.01] \\
(0.07)\end{array}$ & $\begin{array}{l}1.31[1.01-1.70] \\
(0.04)\end{array}$ & $\begin{array}{l}1.20[1.03-1.39] \\
(0.01)\end{array}$ \\
\hline $\begin{array}{l}\text { Mothers education } \\
\text { No education (ref.) }\end{array}$ & 1 & 1 & 1 & 1 \\
\hline $\begin{array}{l}\text { Primary } \\
\text { Secondary+ }\end{array}$ & $\begin{array}{l}0.72[0.56-0.93] \\
(0.01) \\
0.54[0.42-0.68] \\
(<0.001)\end{array}$ & $\begin{array}{l}0.83[0.70-0.97] \\
(0.022) \\
0.70[0.60-0.82] \\
(<0.001)\end{array}$ & $\begin{array}{l}1.03[0.78-1.35] \\
(0.855) \\
0.63[0.48-0.82] \\
(0.001)\end{array}$ & $\begin{array}{l}0.86[0.73-1.01] \\
(0.70) \\
0.64[0.54-0.75] \\
(<0.001)\end{array}$ \\
\hline
\end{tabular}

Wealth index

Poor (ref.)

$1 \quad 1$

1

1

Middle

$$
\begin{aligned}
& 0.61[0.47-0.78] \\
& (<0.001) \\
& 0.59[0.48-0.73] \\
& (<0.001)
\end{aligned}
$$

0.80 [0.70-0.92]

$(0.002)$

0.69 [0.54-0.88] $(0.002)$

$0.60[0.48-0.76]$

$0.59[0.52-0.68]$

ECD

$(<0.001)$

$(<0.001)$

$0.81[0.71-0.93]$

$(0.003)$

0.59 [0.51-0.67]

No (ref.)

1

1

1

Yes

$$
\begin{aligned}
& 0.61[0.47-0.79] \\
& (<0.001)
\end{aligned}
$$

0.866 [0.75-0.99]

$(0.043)$

$0.72[0.55-0.92]$

(0.01)

$(0.28)$

Early education

Yes (ref.)

1

1

1

1

No

1.14 [0.90-1.45]

1.24 [1.08-1.43]

(0.284)

(0.002)

1.29 [1.00-1.65]

1.28 [1.11-1.47]

(0.05)

(0.001)

Read child books $\geq 3$ books (ref.)

$1-1$

1.61 [0.97-2.66]

(0.065)

1.51 [1.17-1.94]

(0.001)
1

1.90 [1.12-3.23]

(0.02)
(0.26)
Nutrition status among under five male and female children according to associate factors
Child disability

Yes (ref.)

1
1
1
1 (continued) 


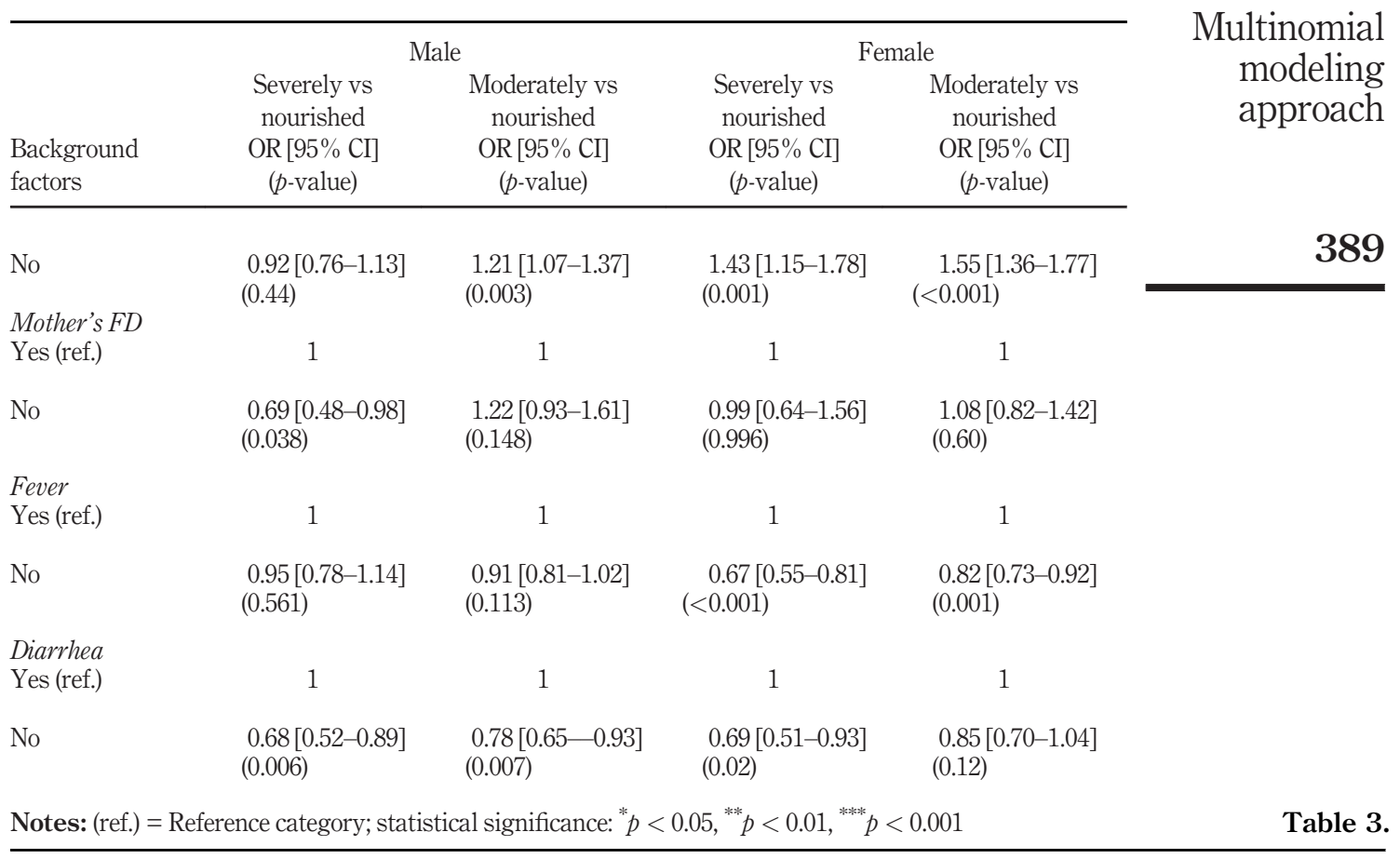

education level of the mother had an inverse association with the wasting status of children and implies that the higher the mother's education level, the less likely a child is to be wasted (Talukder, 2019). The study of India (Srivastava et al., 2012) found that maternal education was a potential risk factor for child nutritional status. This study provides evidence that there was a significant association between women's wealth status and child nutritional status in both male and female children in Bangladesh. This evidence is supported by an earlier study conducted in Bangladesh and observed that children from the wealthiest families were less likely than those from the poorest families to be stunted (Rahman and Sultana, 2019). Children from middle- and upper-income families were less likely to be wasted than children from low-income families (Talukder, 2019).

Rural female children were more likely to be malnourished compared to urban children, however, it is converse for male children. In a study conducted by Pradhan in 2010, where she found that female children were more likely to be stunted compared to male children, similar findings were found (Pradhan, 2010). Rural children were less likely than urban children to be stunted (Rahman and Sultana, 2019). Another research conducted in Indonesia in 1999 indicates a similar form of outcome, with $32 \%$ of rural children malnourished vs $27 \%$ of urban children (Saadah et al., 1999). Sickness is one of the biggest threats to the prevalence of malnutrition, diarrhea and fever (Poda et al., 2017). This research indicates that both male and female children who had no diarrhea and no fever were less likely to be malnourished than children who had diarrhea and fever. However, for both male and female children, diarrhea was considered statistically important, but the fever was found significant only for female children. The diarrheal disease was a significant predictor of wasting and underweight in the study of Ethiopia (Fekadu et al., 2015). 
JHASS 4,5

Surprisingly, except for male children with severe malnutrition, children without disabilities were more likely to be severely and moderately malnourished, and children's disability had a higher significant effect on both severe and moderate malnourished for female children. Several underlying risk factors for malnutrition among disabled children have been reported in various countries (Groce et al., 2014). In Bangladesh, disabled children were vulnerable to malnutrition also do not attend regular school (Jahan et al., 2019).

There were several limitations were arisen in the present study. This cross-sectional study design was not suitable for determining the cause-and-effect relationship between malnutrition and its associated factors. This study is based on the AIC and BIC model selection criteria and we found that the multinomial logistic regression model is better than ordinal logistic regression due to the smallest value of AIC and BIC in this analysis. However, we did not reduce gender variation by applying a multilevel logistic model rather we separately applied multinomial logistic regression to identify potential risk factors for child nutritional status in both male and female children.

\section{Conclusion}

The prevalence of child malnutrition in Bangladesh is still high, especially for female under-five children. This study revealed that mothers with higher education levels, wealthy families and child disability have a significant negative impact on moderate and severe malnutrition for both male and female below five years of age children. Additionally, mother's functional disabilities affect male children. Additionally, poverty rates are still high in Bangladesh, and poverty must be reduced to attain SDG 1, corresponding to improve child malnutrition in these areas, since economic status and child nutrition are inversely related. Policymakers should not only take necessary steps to increase children's nutrition level in the division level of Bangladesh but we should also consider regulating childhood development through the expansion of maternal education, especially secondary and higher education.

On this basis, we conclude that increasing maternal education level, wealth status, child health and development is necessary to overcome the malnutrition problem among children under five in Bangladesh.

\section{References}

Bangladesh Bureau of Statistics (BBS) and UNICEF (2019), Progotir Pathey, Bangladesh Multiple Indicator Cluster Survey 2019, Survey Findings Report, Bangladesh Bureau of Statistics (BBS), Dhaka, Bangladesh.

Das, S. and Rahman, R.M. (2011), "Application of ordinal logistic regression analysis in determining risk factors of child malnutrition in Bangladesh", Nutrition Journal, Vol. 10 No. 1.

Das, S., Rahman, A., Ahamed, A. and Rahman, S.T. (2018), "Multi-level models can benefit from minimizing higher-order variations: an illustration using child malnutrition data", Journal of Statistical Computation and Simulation, Vol. 89 No. 6, pp. 1090-1110.

de Onis, M., Blössner, M. and Borghi, E. (2011), "Prevalence and trends of stunting among pre-school children, 1990-2020”, Public Health Nutrition, Vol. 15 No. 1, pp. 142-148.

Fekadu, Y., Mesfin, A., Haile, D. and Stoecker, B.J. (2015), "Factors associated with nutritional status of infants and young children in Somali region, Ethiopia: a cross-sectional study", BMC Public Health, Vol. 15 No. 1, pp. 1-9.

Felisbino-Mendes, M.S., Villamor, E. and Velasquez-Melendez, G. (2014), "Association of maternal and child nutritional status in Brazil: a population based cross-sectional study", PLoS ONE, Vol. 9 No. 1, p. e87486. 
Ferdous, F., Das, S.K., Ahmed, S., Farzana, F.D., Latham, J.R., Chisti, M.J., Ud-Din, A.I.M.S., Azmi, I.J., Talukder, K.A. and Faruque, A.S.G. (2013), "Severity of diarrhea and malnutrition among under five-year-old children in rural Bangladesh", The American Journal of Tropical Medicine and Hygiene, Vol. 89 No. 2, pp. 223-228.

Groce, N., Challenger, E., Berman-Bieler, R., Farkas, A., Yilmaz, N., Schultink, W., Clark, D., Kaplan, C. and Kerac, M. (2014), "Malnutrition and disability: unexplored opportunities for collaboration", Paediatrics and International Child Health, Vol. 34 No. 4, pp. 308-314.

Haslett, S., Jones, G. and Isidro, M. (2015), Small-Area Estimation of Child Undernutrition in modeling approach Bangladesh, Bangladesh Bureau of Statistics, United Nations World Food Programme and International Fund for Agricultural Development, Dhaka, Bangladesh.

Hume-Nixon, M. and Kuper, H. (2018), "The association between malnutrition and childhood disability in low-and middle-income countries: systematic review and meta-analysis of observational studies”, Tropical Medicine and International Health, Vol. 23 No. 11, pp. 1158-1175.

International Food Policy Research Institute (2015), Global Nutrition Report 2015: Actions and Accountability to Advance Nutrition and Sustainable Development, International Food Policy Research Institute, Washington, DC.

Jahan, I., Karim, T., Al Imam, M.H., Das, M.C., Ali, K.M., Muhit, M. and Khandaker, G. (2019), "Childhood disability and nutrition: findings from a population-based case control study in rural Bangladesh”, Nutrients, Vol. 11 No. 11, p. 2728.

Khadse, R.P. and Chaurasia, H. (2020), "Nutrition status and inequality among children in different geographical regions of Maharashtra, India”, Clinical Epidemiology and Global Health, Vol. 8 No. 1, pp. 128-137.

Kleinbaum, D.G. and Klein, M. (2010), Logistic Regression: A Self-Learning Text, Springer New York, NY.

Kuper, H., Nyapera, V., Evans, J., Munyendo, D., Zuurmond, M., Frison, S., Mwenda, V., Otieno, D. and Kisia, J. (2015), "Malnutrition and childhood disability in Turkana, Kenya: results from a casecontrol study", PLoS One, Vol. 10 No. 12, pp. 1-13.

Mahgoub, S.E., Nnyepi, M. and Bandeke, T. (2006), "Extent types of and the factors related to malnutrition among children under three years of age in Botswana", African Journal of Food, Agriculture, Nutrition and Development, Vol. 6 No. 1.

Megabiaw, B. and Rahman, A. (2013), "Prevalence and determinants of chronic malnutrition among under-5 children in Ethiopia", Int J Child Health Nutr, Vol. 2 No. 3, pp. 230-236.

Mohammed, E.A., Naugler, C. and Far, B.H. (2015), "Emerging business intelligence framework for a clinical laboratory through big data analytics", Emerging Trends in Computational Biology, Bioinformatics, and Systems Biology, pp. 577-602.

Mostafa Kamal, S.M., Rosliza, A.M. and Aynul, M. (2010), "Effects of wealth on nutritional status of preschool children in Bangladesh", Malaysian Journal of Nutrition, Vol. 16 No. 2, pp. 219-232.

National Institute of Population Research and Training (NIPORT), Mitra and Associates and Macro International (2009), Bangladesh Demographic and Health Survey 2007, NIPORT, Mitra and Associates, and ICF International, Dhaka, Bangladesh.

Negash, C., Whiting, S.J., Henry, C.J., Belachew, T. and Hailemariam, T.G. (2015), "Association between maternal and child nutritional status in hula, rural Southern Ethiopia: a cross sectional study", PLoS One, Vol. 10 No. 11, p. e0142301.

Poda, G.G., Hsu, C.-Y. and Chao, J.C.-J. (2017), "Factors associated with malnutrition among children $<5$ years old in Burkina Faso: evidence from the demographic and health surveys IV 2010", International Journal for Quality in Health Care, Vol. 29 No. 7, pp. 901-908.

Pradhan, A. (2010), "Factors associated with nutritional status of the under five children", Asian Journal of Medical Sciences, Vol. 1 No. 1, pp. 6-8. 


\section{JHASS 4,5}

Rahman, A. (2016a), "Significant risk factors for childhood malnutrition: evidence from an Asian developing country", Science Journal of Public Health. Special Issue: Childhood Malnutrition in Developing Countries, Vol. 4 Nos 1/1, pp. 16-27.

Rahman, M. (2016b), "Association between order of birth and chronic malnutrition of children: a study of nationally representative Bangladeshi sample”, Cadernos De SaúdePública, Vol. 32 No. 2.

Rahman, M. and Sultana, P. (2019), "Distribution and risk factors of child malnutrition in Bangladesh based on Bangladesh demographic and health survey-2014 data", Journal of Biometrics and Biostatistics, Vol. 10 No. 1, pp. 1-8.

Rayhan, M.I. and Khan, M.S.H. (2006), "Factors causing malnutrition among under five children in Bangladesh”, Pakistan Journal of Nutrition, Vol. 5 No. 6, pp. 558-562.

S, Y. and K, I. (2016), "Prevalence and determinants of undernutrition among school age slum children in Dhaka city", Journal of Nutrition and Health Sciences, Vol. 3 No. 2.

Saadah, F., Waters, H. and Heywood, P. (1999), Indonesia: Undernutrition in Young Children, Watching Brief, East Asia the Pacific Region. World Bank.

Saha, U.R., Chattapadhayay, A. and Richardus, J.H. (2019), "Trends, prevalence and determinants of childhood chronic undernutrition in regional divisions of Bangladesh: evidence from demographic health surveys, 2011 and 2014", PLoS One, Vol. 14 No. 8, pp. 1-18.

Shrestha, A., Bhusal, C.K., Shrestha, B. and Bhattarai, K.D. (2020), "Nutritional status of children and its associated factors in selected earthquake-affected VDCs of Gorkha district", International Journal of Pediatrics, Vol. 2020, pp. 1-10.

Srivastava, A., Mahmood, S.E., Srivastava, P.M., Shrotriya, V.P. and Kumar, B. (2012), "Nutritional status of school-age children - a scenario of urban slums in India", Archives of Public Health, Vol. 70 No. 1.

Talukder, A. (2017), "Factors associated with malnutrition among under-five children: illustration using Bangladesh demographic and health survey, 2014", Children, Vol. 4 No. 10, p. 88.

Talukder, A. (2019), "Risk factors associated with wasting among under-5 children residing in urban areas of Bangladesh: a multilevel modelling approach", Journal of Public Health, Vol. 29 No. 3, pp. 1-7.

Toma, A.S., Talukder, A., Khan, S.S. and Rahman Razu, S. (2018), "An assessment of the association between antenatal care and child malnutrition in Bangladesh", Family Medicine and Primary Care Review, Vol. 20 No. 4, pp. 373-378.

UNICEF (2018), "Malnutrition in children", available at: http://data.unicef.org/topic/nutrition/ malnutrition/\# (accessed 9 Feb. 2021).

UNICEF (2020), "Bangladesh sees sharp decline in child malnutrition, while violent disciplining of children rises, new survey reveals", available at: www.unicef.org/bangladesh/en/press-releases/bangladeshsees-sharp-decline-child-malnutrition-while-violent-disciplining-children (accessed 12 Feb. 2021).

World Health Organization (2018), "Children: reducing mortality", available at: www.who.int/newsroom/fact-sheets/detail/children-reducing-mortality (accessed 9 Feb. 2021).

World Health Organization (2020), "Malnutrition", available at: www.who.int/news-room/fact-sheets/ detail/malnutrition (accessed 9 Feb. 2021).

\section{Corresponding author}

Iqramul Haq can be contacted at: iqramul.haq@sau.edu.bd

For instructions on how to order reprints of this article, please visit our website:

www.emeraldgrouppublishing.com/licensing/reprints.htm

Or contact us for further details: permissions@emeraldinsight.com 